\title{
Correction to: Handbook of Engineering Practice of Materials and Corrosion
}

\section{Correction to: J. -C. Eun, Handbook of Engineering Practice of Materials and Corrosion, https://doi.org/10.1007/978-3-030-36430-4}

This book was inadvertently published without updating the following (or with the following errors).

Table of contents was erroneously published.

Figure 2.150 was incorrectly published.

Tables $2.73,2.111,4.21,4.112,5.16$, and 5.43 were published with errors.

Table citations in-text in Chapters 2, 4, and 5 were erroneously published.

The above corrections have now been updated throughout the book.

The updated online version of this chapters can be found at https://doi.org/10.1007/978-3-030-36430-4_2

https://doi.org/10.1007/978-3-030-36430-4_4

https://doi.org/10.1007/978-3-030-36430-4_5

https://doi.org/10.1007/978-3-030-36430-4

(C) Springer Nature Switzerland AG 2020 